\title{
Remdesivir for Covid-19 pneumonia in patients with severe chronic kidney disease: Case series and review of the literature
}

\author{
Ahmad Al Bishawi ${ }^{1}$, Hamad Abdel Hadi $^{1}$, Eman Elmekaty ${ }^{1}$, Musaed Al Samawi ${ }^{1}$, Arun \\ Nair $^{1}$, mohamed aboukamar ${ }^{1}$, Muna AlMaslamani², and Alaaeldin Abdelmajid ${ }^{3}$ \\ ${ }^{1}$ Hamad Medical Corporation \\ ${ }^{2}$ Hamad Medical Corp \\ ${ }^{3}$ Hamad General Hospital
}

January 3, 2022

\begin{abstract}
Remdesivir was the first antiviral agent to receive FDA authorization for severe COVID-19 management, which restricts its use with severe renal impairment due to concerns that active metabolites might accumulate, causing renal toxicities. With limited treatment options, available evidence on such patient groups is important to assess for future safety.
\end{abstract}

\section{Hosted file}

Remdesivir_-_Final- Submitted.docx available at https://authorea.com/users/438539/articles/ 551402-remdesivir-for-covid-19-pneumonia-in-patients-with-severe-chronic-kidney-diseasecase-series-and-review-of-the-literature 